\title{
Repensando a redistribuição Nancy Fraser e a Economia Política
}

\author{
Rethinking redistribution \\ Nancy Fraser and Political Economy \\ Repensando la redistribución \\ Nancy Fraser y la Economía Política
}

Enrico Paternostro Bueno da Silva ${ }^{1}$

\begin{abstract}
Resumo: Partindo da polêmica entre Axel Honneth e Nancy Fraser sobre a teoria do reconhecimento, o artigo tem como objeto a abordagem da autora estadunidense para a Economia Política. Após discutir o tratamento conferido ao tema em seus artigos que compõem a coletânea Redistribution or recognition, bem como as objeções a ele levantadas, busca-se investigar em que medida as revisões ulteriores propostas por Fraser foram suficientes e satisfatórias para superar as principais limitações e questões não-respondidas de seu modelo.
\end{abstract}

Palavras-chave: Redistribuição; Economia Política; Justiça social.

\begin{abstract}
Based on Axel Honneth and Nancy Fraser's controversy about the theory of recognition, the article focuses on the North-American author's approach to Political Economy. After discussing the given treatment to the issue in her articles that compose Redistribution or recognition, as well as the objections to it, this work seeks to investigate if the subsequent revisions achieved by Fraser were enough and satisfactory to overcome the main limitations and unanswered questions of her critical model.
\end{abstract}

Keywords: Redistribution; Political Economy; Social justice.

Resumen: A partir de la polémica entre Axel Honneth y Nancy Fraser con respecto de la teoría del reconocimiento, el artículo tiene como objeto el abordaje de la autora estadunidense para la Economía Política. Después de discutir el tratamiento conferido al tema en sus artículos que componen la colección Redistribution or recognition, así como las objeciones a él planteadas, se busca investigar si las revisiones posteriores propuestas por Fraser fueron suficientes y satisfactorias para superar las principales limitaciones y cuestiones no respondidas de su modelo.

Palabras clave: Redistribución; Economía Política; Justicia social.

\footnotetext{
${ }^{1}$ Universidade Estadual de Campinas (Unicamp, Campinas, SP, Brasil). autor.dados_biográficos
} 
Nos últimos anos, muito se tem produzido sobre os conceitos de redistribuição e reconhecimento, a partir do debate protagonizado por Axel Honneth e Nancy Fraser. Nascida de uma divergência da filósofa norteamericana em relação ao monismo moral da teoria do reconhecimento, a disputa se tornou paradigmática aos estudos sobre justiça social em perspectiva crítica. No Brasil sua recepção foi notável, tendo mobilizado filósofos e cientistas sociais tanto para a discussão de seu conteúdo teórico quanto para a tentativa de operacionalização do mesmo na explicação social. ${ }^{1}$

Tratando-se de um debate já analisado sob diversos recortes, faz-se relevante o exercício de extrapolar o já dito através de um estudo das nuances ulteriores nos argumentos dos autores, de modo a averiguar em que medida os limites encontrados de parte a parte foram superados. Este trabalho visa participar de tal empreendimento. Especificamente, busca analisar os contornos que adquiriu o tema da redistribuição na produção de Fraser desde a publicação de Redistribution or recognition (2003), obra conjunta com Honneth em que o diálogo é apresentado. A autora, que já havia realizado valiosos estudos em filosofia política anteriormente, tem mobilizado sua heterodoxa gama de interlocução teórica para buscar respostas aos problemas identificados em seus escritos e novas explicações para questões sociais emergentes.

Assim, considerando trabalhos mais recentes de Fraser, propõe-se averiguar em que medida as formulações tardias respondem satisfatoriamente às objeções postas. Parte dessas críticas se encontra no próprio Honneth; outras serão apresentadas a seguir. Poder-se-ia levantar as problematizações referentes ao dualismo da materialidade-simbolicidade (Young, 1997; Butler, 1998; Alcoff, 2007), à fundamentação da normatividade (Forst, 2008) e às limitações no tratamento de questões referentes às instituições e arranjos legais (Olson, 2008; Zurn, 2008). Contudo, considerando o volume de refutações à proposta apresentada na obra conjunta e as diversas respostas da autora, $\mathrm{o}$ recorte deste artigo focaliza as questões relativas à economia política.

\section{Justiça social enquanto paridade participativa}

Embora seja Charles Taylor (2000) um dos grandes responsáveis por revigorar o conceito hegeliano de reconhecimento e mobilizá-lo para a análise do conflito social, são as formulações de Honneth e Iris Young que aparecem como antítese da polêmica iniciada por Fraser. Em especial, está em jogo o argumento de Luta por Reconhecimento, que pode ser entendido como

\footnotetext{
${ }^{1}$ Ver os trabalhos de Jessé Souza (2000), Patrícia Mattos (2006), Ricardo Fabrino Mendonça (2007), Josué Pereira da Silva (2008), Céli Regina Jardim Pinto (2008) e Luiz Gustavo da Cunha de Souza $(2009 ; 2013)$.
} 
uma tentativa de levar a noção hegeliana de intersubjetividade às últimas consequências. Com sua formulação, Honneth quer suprir o que considera um défice não superado na Teoria Crítica: as interações sociais conduzidas pelos atores na vida cotidiana e sua vinculação com os processos de formação identitária dos indivíduos.

Ambicionando encontrar as condições intersubjetivas de mudanças sociais aproximativas do horizonte normativo da eticidade, e contrapondo-se a teorizações que buscam a causa última do conflito social em interesses utilitários ou de autoconservação, Honneth estuda os fundamentos morais subteorizados que estariam nas bases motivacionais das lutas sociais. Para tal, edifica sobre uma antiga tipologia hegeliana, à qual incorpora uma fundamentação pós-metafísica recorrendo aos estudos psicanalíticos de Winnicott e à psicologia social de Mead, a tese central de que a formação da identidade humana supõe uma experiência de reconhecimento intersubjetivo.

Seguindo o jovem Hegel, o autor propõe que a formação das relações de reconhecimento pelo sujeito se dá em três momentos: as relações amorosas, de teor afetivo; as relações jurídicas, de teor cognitivo; e as relações éticas de solidariedade, cujo caráter é de uma "intuição intelectual", o afeto tornado racional. Seguindo essa tripartição, uma construção não patológica da personalidade exigiria, no primeiro nível, uma separação bem-sucedida entre a criança e sua mãe, a partir da qual se pode constituir autonomia na relação entre o Eu e o Outro concreto. No segundo nível, demanda-se o reconhecimento do indivíduo pela institucionalidade enquanto sujeito de direitos, seu reconhecimento pelo Outro generalizado enquanto pessoa de igual valor moral. O terceiro nível, por sua vez, alude à apreciação comunitária dos atributos particulares do indivíduo, pela qual este pode alcançar alguma estima social por meio de relações solidárias: trata-se de uma forma de reconhecimento que demanda "a confirmação a cada um não apenas como membro de uma coletividade, mas também como sujeito biograficamente individuado" (Honneth, 2003a, p. 139).

Honneth entende que o caminho que poderia levar à confirmação de tais formas de reconhecimento se consolida historicamente de modo conflitivo, através das lutas que têm como horizonte normativo a superação dos obstáculos relacionais à autorrealização, isto é, o "processo em que um sujeito desenvolve capacidades e propriedades de cujo valor para o meio social ele pode se convencer com base nas reações de reconhecimento de seu parceiro de interação" (Honneth, 2003a, p. 147-148). Segue-se daí a concepção que enxergará na negação de uma "autorrelação prática", que permitiria ao 
indivíduo uma formação identitária não-deformada, o impulso motivacional que teria sido ignorado por teorias utilitaristas. $\mathrm{O}$ dano imputado ao indivíduo mediante formas de desrespeito, ao obstacularizar sua autoconfiança, autorrespeito ou autoestima, poderia conduzi-lo - sob dadas circunstâncias - a se associar com outros semelhantemente lesados para a ação coletiva. Haveria, então, uma ponte entre a negação do reconhecimento manifesto em formas de desrespeito e a formação de grupos sociais politicamente ativos.

Aqui, não cabe tanto a análise dessa proposição quanto a refutação de Fraser e sua alternativa. Aproximando-se da crítica de Benhabib (2002) a Taylor, Fraser entende que esse caminho conduz a uma equiparação entre política de reconhecimento e política de identidade, posto que encara a luta contra a depreciação cultural de determinados grupos como uma forma de remediar as autopercepções negativas. Para ela, isso carregaria uma série de problemas: a) seria insuficiente para o tratamento socioestrutural das injustiças sociais fundadas na economia política, endossando uma tendência contemporânea de deslocamento das teorias e práticas políticas igualitárias por demandas construídas sob horizontes culturalistas ou diferencialistas (diagnosticado como "deslocamento da redistribuição pelo reconhecimento" enquanto paradigma de justiça); b) poderia culminar em formas de reificação das identidades coletivas e servir de suporte a comunitarismos repressivos, posto que prescinde de um referencial deontológico para a justificação das demandas; c) tenderia ao psicologismo, na medida em que a crítica da injustiça social seria realizada segundo seus impactos sobre as distorções da autocompreensão dos indivíduos e não sobre os condicionantes sociais que as engendram; d) culminaria na exigência implausível de um direito de igual estima social a todos os indivíduos.

Em uma primeira alternativa proposta, Fraser $(1995$; 1997) recorre a um dualismo moral inspirado tanto na dissociação habermasiana entre reprodução material e simbólica da sociedade, quanto no diagnóstico de uma cisão entre movimentos sociais que propõem políticas igualitaristas e aqueles de perfil identitário. A autora levanta a discussão sobre como essa conciliação pode ser possível de modo a superar o dilema entre a "redistribuição" e o "reconhecimento"; indica que o único caminho que pode construir uma política não contraditória passa pela radicalização da redistribuição enquanto socialismo (reestruturação profunda das relações de produção) e do reconhecimento enquanto desconstrução (desestabilização das diferenciações essencialistas em nome de identificações fluidas e livres). Tal seria necessário sobretudo aos movimentos em que o dilema é mais patente, como as lutas feminista e antirracista, dado que os diagnósticos levantados pelos críticos do 
androcentrismo e da racialização costumam apontar para imbricações entre determinações de cunho material e simbólica.

Já se mostra que Fraser dota o "reconhecimento" de uma conceituação bastante distinta da de Honneth: enquanto para ela o conceito abriga demandas conflituosamente colocadas em nome de identificações culturais, em Honneth o termo aparece como conceito moral fundamental. Posteriormente, tentando qualificar filosoficamente seu quadro conceitual e revisar seu questionado dualismo moral, Fraser publica em 2000 e 2001 dois textos em que o modelo é revisto, constituindo o cerne do posicionamento que defenderá no primeiro capítulo do livro conjunto: trata-se de Rethinking recognition (Fraser, 2000) e Recognition without etics? (Fraser, 2007a). Neles, argumenta que a dificuldade de conciliação entre os dois paradigmas de justiça tem como pano de fundo filosófico a complexidade de articulação entre a "igual dignidade moral" e o "respeito à diferença" como núcleos normativos para uma sociedade justa: as propostas vinculadas ao primeiro se aproximariam da concepção kantiana de moralidade; o segundo seria mais próprio de teorias que resgatam a eticidade hegeliana.

Sua alternativa passa por submeter ambas as esferas a um único imperativo moral, a que denomina paridade participativa, conceito sobre o qual vem trabalhando desde sua juventude. Em estudos realizados na década de 1980, a expressão havia sido mobilizada para aludir a uma norma desenvolvida pelo modelo burguês de esfera pública analisado por Habermas, segundo a qual todos os participantes do debate público deveriam momentaneamente suspender as desigualdades extradiscursivas de modo que a única coerção sobre a opinião alheia fosse a do melhor argumento. Fraser (1990) entende essa norma como ideológica: a única forma de superar a disparidade discursiva na esfera pública seria através da supressão das disparidades sociais fora dela, devendo estas serem francamente tematizadas no debate. Prolonga, assim, o conceito para além da autocompreensão normativa da esfera pública, convertendo a paridade participativa em imperativo que deve permear todos os espaços de interação social para que seja realidade efetiva nos processos deliberativos formais e informais que subjazem à formação pública da vontade.

Assim, assumindo para seu trabalho o princípio universal de igual valor moral enquanto premissa da justiça, Fraser descreve a paridade participativa como condição de que os membros adultos de uma sociedade possam participar como parceiros na interação social. Das relações domésticas ao debate público, passando pelo mercado de trabalho e espaços deliberativos no interior do estado, "o requerimento moral é que aos membros da sociedade seja garantida a possibilidade de paridade, se e quando eles escolherem participar em uma 
dada atividade ou interação" (Fraser, 2007a, p. 118). Nesse registro, remediar injustiças significa superar os arranjos sociais que impedem a paridade, eliminar os obstáculos à igualdade de condições na interação.

As demandas populares por redistribuição e reconhecimento seriam interpretadas, sob esse novo arcabouço teórico, como respostas aos impedimentos objetivos e intersubjetivos à participação paritária, já que sua efetivação exige tanto uma distribuição dos recursos materiais que assegure independência e voz aos indivíduos, quanto a superação de hierarquias de valoração cultural. Desse modo, Fraser recorre a Weber (1982) para reconceitualizar as lutas por reconhecimento, tomando-as como resultantes de uma forma de estratificação social fundada em hierarquias de status. $\mathrm{O}$ referencial normativo da paridade participativa passa a ratificar, portanto, lutas por reconhecimento que combatem os "padrões institucionalizados de valoração cultural":

Se e quando tais padrões instituem atores como pares, capazes de participar paritariamente um com o outro na vida social, então podemos falar de reconhecimento recíproco e de igualdade de status. Quando, ao contrário, eles instituem alguns atores como inferiores, excluídos, inteiramente outros, ou simplesmente invisíveis - ou seja, como menos do que parceiros integrais em interação social - então podemos falar em não-reconhecimento e subordinação de status (Fraser, 2000, p. 113. Tradução minha).

Notadamente, o estatuto conceitual e o conteúdo normativo do reconhecimento sofrem oscilações marcantes em relação ao quadro honnethiano. Ao repensar o reconhecimento como status, propondo um modelo capaz de criticar sua negação sem reivindicar particularismos grupais, Fraser busca superar o supramencionado dilema no plano da fundamentação normativa: justificáveis são "políticas de reconhecimento" que miram o desmantelamento das estratificações estamentais, independentemente de mobilizarem ou não identidades coletivas e especificidades em seu processo constitutivo. Tal concepção, argumenta, se mostra mais favorável à conciliação com demandas que visam a superação das desigualdades materiais a partir de uma perspectiva da igualdade humana. Os problemas começam nesse ponto do argumento: diferentemente do esforço empreendido em explanar uma concepção normativa de luta justificável por reconhecimento, a autora não constrói um referencial teórico tão sólido e extenso para lidar com a dimensão distributiva da injustiça social. Ou, pelo menos, não o faz até Redistribution or recogntion. 


\section{Problemas no debate com Honneth}

Mesmo supondo que tal alternativa tenha superado problemas encontrados na teoria do reconhecimento, ela também se mostrou vulnerável a objeções variadas. A resposta de Honneth, ainda no livro de 2003, talvez seja a mais conhecida; seu argumento se desenvolve por três vias simultâneas: defende que Fraser interpretou equivocadamente sua formulação, demonstra porque sua teoria não deixa de contemplar os problemas de cunho políticoeconômico e aponta problemas na teorização da autora.

Cabe focalizar o terceiro ponto, sobre o qual é possível enumerar com apoio da excelente síntese de Mendonça (2007) - as seguintes críticas: a) Honneth afirma que "há algo de arbitrário" na proposta dualista, alegando fragilidades na fundamentação; b) concebendo que o capitalismo enquanto sistema econômico é regido normativamente, argumenta que a distribuição de recursos tem uma dimensão moral de fundo, uma valoração subjacente a seus critérios; c) acusa a autora de generalizar a experiência norte-americana, inclusive em seu diagnóstico da cisão entre "esquerda cultural" e "esquerda social"; d) recusa a noção filosófica de um "reconhecimento sem ética", considerando descabida uma concepção de justiça sem uma alguma suposição prévia de boa vida.

A crítica de Honneth, grosso modo, recai sobre limitações ou contradições contidas naquilo que Fraser escreve, com ênfase sobre os pontos que desafiam sua teorização. Entretanto, pode-se levar em conta aquilo que Fraser não escreve, ou seja, as lacunas e questões deixadas em aberto pelo argumento desenvolvido até 2003. Pode-se mencionar, por exemplo, que mesmo assumindo a subsunção do dualismo socioanalítico pelo monismo normativo da paridade participativa, os elementos formais e institucionais da disputa política têm pouco espaço, ou quase nenhum, para uma proposta que se coloca como "teoria da justiça" (Olson, 2008; Zurn, 2008). Ademais, pode-se apontar que, ao se debruçar na construção de um novo conceito de reconhecimento e conduzir o debate com Honneth para esse terreno, Fraser não oferece uma formulação consistente para os fundamentos político-econômicos da negação à paridade; por conseguinte, seu trabalho acusaria uma fragilidade na discussão das imbricações concretas entre os dois momentos conceituais de seu modelo, reforçando o apontamento de Honneth quanto ao problema da dimensão moral do capitalismo e sua reprodução.

No que tange à noção de redistribuição em si, enquanto horizonte para a superação da face material da injustiça, é possível levantar outra limitação a partir de um referencial bibliográfico marxista: a de restringir a crítica da 
economia política ao seu momento distributivo, minimizando o momento produtivo, o trabalho abstrato e a divisão social do trabalho. No chamado Caderno $M$, que acompanha a edição brasileira dos Grundrisse, Marx (2011) dedica-se exatamente às mediações entre os momentos conceituais da produção, troca, distribuição e consumo sob o modo de produção capitalista, de modo a indicar sua concepção dialética de totalidade. Esta, para além de colocar em questão as mediações entre esferas aparentemente independentes da vida social (política, religião, Direito, etc.) e destas com a determinação central posta pela "produção dos meios de vida", indica ser implausível analisar separadamente e estaticamente os principais momentos da economia política. Embora Fraser mencione, em suas primeiras formulações sobre o tema, que as demandas agrupadas sob o "paradigma popular" da redistribuição abrangem as dimensões da exploração (apropriação dos frutos do trabalho alheio), marginalização econômica (obrigação de trabalho indesejável e injustamente remunerado ou negação ao assalariamento) e privação (negação de um padrão material adequado de vida), não chega a teorizar sobre nenhum desses três momentos conceituais, as concatenações entre eles e deles com os problemas do reconhecimento. Mais: na medida em que essa tripartição interna acaba sendo pouco referida, deixa entrever uma priorização do momento distributivo do processo econômico em relação ao produtivo.

Finalmente, e ainda seguindo na linha das ausências, há pouco espaço em seus textos de Redistribution or recognition para a discussão dos fundamentos transnacionais da injustiça econômica. Problemas como o imperialismo, a divisão internacional do trabalho, a globalização e a articulação do Capital com modos de produção "pré-modernos" nas sociedades periféricas não parecem importar muito para a explicação que Fraser provê, de modo que seu trabalho de então recai em certo "nacionalismo metodológico" que a impede de discutir as determinações transnacionais da negação à paridade participativa.

Nos textos publicados a partir de 2004, entretanto, alguns desses pontos são revistos e reconceitualizados, culminando em outra reorganização teórica do modelo anterior. Abrigando a discussão acerca dos impactos da globalização sobre os caminhos concretos de efetivação da justiça social, Fraser tenta oferecer respostas às críticas e às mudanças conjunturais observadas. Cabe abordá-las.

\section{Repensando a redistribuição}

Dentre as revisões e expansões realizadas pela autora, destaca-se a coletânea Scales of justice, de 2009, em que são analisadas as implicações da globalização e da geopolítica pós-Guerra Fria sobre uma concepção 
anteriormente vigente de justiça social (denominada keynesiana-westfaliana). Outros artigos, publicados isoladamente nos anos subsequentes, também marcam a emergência de novas percepções quanto à economia política e a proteção social sob o capitalismo neoliberal. Para sumarizar as revisões que aqui interessam, é possível elencar três principais pontos de reformulação: a) a discussão mais aprofundada quanto à necessidade de pensar redistribuição e reconhecimento de modo imbricado nas políticas de proteção social; b) a colocação da "representação" enquanto terceira dimensão da justiça; c) a teorização das condições não imediatamente econômicas que ensejam a perpetuação do modo de produção capitalista.

a) Para aprofundar sua crítica da cisão entre políticas distributivas e de reconhecimento, Fraser retoma argumentos anteriormente desenvolvidos quanto ao caráter simbolicamente disputado das necessidades sociais (Fraser, 1989), discute a constituição contemporânea de "afinidades eletivas perversas" entre a agenda econômica neoliberal e tendências culturalistas do feminismo (Fraser, 2009b) e propõe uma concomitante subsunção e superação crítica da concepção de proteção social desenvolvida por Karl Polanyi (2001), que tem em vista os momentos de crise do capitalismo e as perspectivas de regulação da economia pelo controle societal. Procura, com isso, dar conta da questão dos fundamentos morais do capitalismo ao mesmo tempo em que explicita os problemas de uma luta por reconhecimento desvinculada da dimensão distributiva.

O ponto de partida de Fraser é o modo como Polanyi (2001) teorizou sobre a crise: entende que o economista húngaro não a compreendeu apenas como problema oriundo do abalo econômico mediante suas contradições internas, mas antes relacionada à desintegração de comunidades, desfazimento de solidariedades e destruição da natureza. Em sua teorização, Polanyi (2001) tratara de duas formas estilizadas de relação entre economia e sociedade: um "mercado enraizado", no qual se busca sua subordinação e controle pela moral presente na sociedade; ou um "mercado desenraizado", livre, não regido por instâncias exteriores às econômicas. Assim, a disputa fundamental em tempos de crise seria entre os esforços dos interesses do capital em desenraizar os mercados e os contra-esforços em proteger a sociedade, a natureza e a organização produtiva de um ideário de autorregulação mercantil. A tal disputa o autor denomina movimento duplo.

Para Fraser, a teorização tem a contribuir para interpretar a conjuntura recente, mas carrega problemas: entende que Polanyi (2001) romanceia a sociedade e ajuda a absolver formas de proteção social que ratificam 
dominações; na medida em que as injustiças ancoradas na "sociedade" (como o androcentrismo) são codificadas em proteções sociais - como a própria Fraser argumenta desde a juventude ${ }^{2}-$, seria indevida a preferência do autor pela "proteção social" pura e simplesmente. Entendendo que não basta a uma Teoria Crítica enraizar a economia nos valores vigentes, Fraser propõe transformar a concepção em movimento triplo: o terceiro elemento seria a emancipação. Segundo ela, se a mercantilização se opõe à regulação econômica pela sociedade e a proteção social se opõe à desintegração social pelos mercados desregulados, a emancipação quer se opor às formas de dominação de onde quer que venham: da "sociedade" ou da "economia". Não coincidindo exatamente nem com a mercantilização pura, nem com uma proteção social que reitera normas opressivas, as lutas por emancipação se distinguiriam de ambos polos: não buscam "defender as proteções sociais existentes, mas, sobretudo, procuram transformar o modo de proteção" (Fraser, 2011, p. 623).

Utilizando o jargão construído anteriormente, pode-se dizer que enquanto políticas voltadas exclusivamente à redistribuição podem resultar em rebaixamento de status, políticas centradas apenas na dimensão do reconhecimento coadunariam facilmente com reformas neoliberais que, ao aprofundar a disparidade distributiva, reforçariam a dominação existente e obstacularizaria saídas emancipatórias. Para Fraser, este é o caso de algumas vertentes do feminismo, movimento que padeceria de uma ambivalência entre, de um lado, a defesa de uma mercantilização que (em aparência) reconhece a igualdade das mulheres e, de outro, formas androcêntricas de proteção social que (em aparência) logram a solução de questões materiais imediatas. Entendendo que a mercantilização neoliberal tem extraído força e legitimação junto a organizações do movimento, reforça seu imperativo de busca por políticas que vinculem positivamente redistribuição e reconhecimento.

b) Para responder às objeções que acusam a ausência de um espaço específico para as problemáticas político-institucionais e tratar das implicações

\footnotetext{
${ }^{2}$ Fraser (1989) destaca a separação generificada que ocorre no sistema estadunidense de seguridade social; demonstra haver dois subsistemas implícitos. O primeiro é orientado a indivíduos e se vincula à participação no trabalho assalariado (seguro-desemprego, previdência, seguro de saúde etc.); o segundo é orientado a cuidadores de casa e se vincula a questões do cuidado doméstico (auxílio a famílias com filhos dependentes, auxilio de alimentação etc.). Recorrendo a dados empíricos, a autora argumenta que: o primeiro subsistema é majoritariamente masculino e o segundo feminino; os programas reforçam papeis tradicionais de gênero ao trazerem suposições relativas à divisão sexual do trabalho; e o primeiro subsistema é composto de programas administrados nacionalmente e abrangendo uniformemente todo o país, enquanto o segundo é descentralizado, de aplicação difusa, irregular e com exigências estigmatizantes aos atendidos.
} 
da globalização sobre o que se sói entender por justiça social, Fraser propõe, com o conceito de representação, um terceiro tipo de requerimento normativo à paridade participativa. Ainda concebendo que o dilema central da justiça hoje ocorre entre imperativos de redistribuição e de reconhecimento, deixa de entender que esses dois eixos esgotem os recortes analíticos da injustiça nas sociedades democráticas. As chamadas "lutas por representação", assim, seriam resultantes de problemáticas referentes "à natureza da jurisdição do estado e das regras de decisão pelas quais ele estrutura as disputas sociais" (Fraser, 2009, p. 19), discutindo em que medida tais regras permitem a exclusão de determinados atores de debate político. O que subjaz a inclusão dessa terceira dimensão é a constatação de que as normas institucionais-formais de mediação das disputas podem encerrar disparidades entre os participantes da interação. Concisamente, essa dimensão política da representação mira duas instâncias da justiça: o critério de pertencimento social, a circunscrição de quem conta como membro do grupo dos legitimados a reivindicar redistribuição ou reconhecimento; e o estabelecimento das regras decisórias, os procedimentos legítimos de apresentação e resolução das disputas, determinando como as reivindicações devem ser introduzidas no debate e julgadas.

Os problemas da representação seriam, para a autora, especialmente patentes em tempos de globalização, em que se enfraquece a soberania do antigo estado keynesiano das sociedades capitalistas centrais e se fazem cada vez mais manifestas "fontes transnacionais de injustiça", seja em termos de redistribuição ou de reconhecimento. Contudo, ao mesmo tempo em que os fundamentos sociais das disparidades participativas são gestados em escalas cada vez mais variadas (local, nacional, regional, global) - ou, ainda, pela interseção de processos em múltiplas escalas -, o ideário vigente de justiça e seus principais instrumentos ainda se encontram demasiadamente vinculados ao estado nacional. Tal dissonância, alcunhada pela autora de "enquadramento desajustado", estaria engendrando novos problemas de representação, posto que o estatuto de cidadão nacional se revela cada vez menos suficiente para a colocação dos sujeitos no cenário da disputa política. Por conseguinte, aqueles que se beneficiam de uma economia política estruturalmente injusta (grandes corporações, investidores, especuladores, magnatas herdeiros etc.) se veem mais protegidos da regulação social, encontrando condições mais favoráveis para a reprodução e ampliação de uma disparidade que os favorecem. Ao mesmo tempo, classes e grupos subalternizados têm reduzidas suas condições de reivindicação e exercício de controle social democrático sobre o sistema. 
c) A oscilação mais marcante da autora para a economia política, porém, talvez tenha sido trazida com o texto de 2014 chamado "Por trás do laboratório secreto de Marx" (Fraser, 2015). Considerando que o pensamento de Marx oferece recursos conceituais indispensáveis para teorizar sobre as contradições atuais do capitalismo, a autora pondera que alguma revisão é necessária para poder dar conta de outros eixos de desigualdade social que subjazem aos conflitos contemporâneos por justiça social.

A principal chave de leitura mobilizada para defender uma concepção ampliada de capitalismo - e, por conseguinte, ampliar o escopo distributivo clássico enquanto remediação das injustiças - se encontraria no próprio Capital. Segundo a autora, após uma explanação sistemática dos mecanismos ocultos da exploração capitalista, o capítulo 24 da obra marxiana, referente à "acumulação primitiva", opera um giro epistêmico na análise, apontando a expropriação (a violência explícita e o roubo de fato) como condição de fundo necessária para autovalorização do capital. Com esse movimento, Marx teria demonstrado que a explicação do capitalismo não deveria se restringir ao desvelamento das condições exploratórias camufladas pela "troca de equivalentes", mas também caberia tratar das precondições não imediatamente econômicas presentes não só na origem, mas no funcionamento corrente do capitalismo mundial.

Analogamente, outro giro epistêmico teria sido desenvolvido pelo pensamento marxista ao longo do século 20: trata-se da discussão da reprodução social, que apontou as condições de fundo "imateriais" para a manutenção do domínio capitalista ao longo das gerações; isto é, a produção e manutenção de laços sociointegradores que favorecem a perpetuação do modo de produção. Seguindo seus trabalhos anteriores, Fraser indica as determinações de gênero que plasmam os processos reprodutivos:

O central aqui é o trabalho de socialização da juventude, a construção das comunidades, a produção e a reprodução dos significados compartilhados, as disposições afetivas e os horizontes de valor que estruturam a cooperação social. Nas sociedades capitalistas, boa parte, embora não tudo, destas atividades ocorrem fora do mercado, nos lares, nas vizinhanças e em algumas instituições públicas, incluindo escolas e creches; e boa parte disto, embora não tudo, não assume a forma de trabalho remunerado. [...] O trabalho remunerado não poderia existir sem o trabalho doméstico, a criação de filhos, a educação escolar, o cuidado afetivo e uma série de outras atividades que ajudam a produzir as novas gerações de trabalhadores, a reabastecer as existentes, a manter laços sociais e compreensões compartilhadas (Fraser, 2015, p. 713). 
Para além dessas duas descobertas mais conhecidas da crítica social, a autora entende que as teorias críticas também promoveram outros dois giros epistêmicos na análise: quanto ao parasitismo em relação à natureza, que subjaz ao modo de produção capitalista e tem sido amplamente discutido pelo ecossocialismo; e quanto às condições políticas que possibilitaram o estabelecimento de normas constitutivas e necessárias à "troca de equivalentes". Quanto ao primeiro aspecto, Fraser recorre aos estudos que acusam a emergência de uma nova era geológica - o antropoceno segundo os quais a atividade humana, em suas suposições de uma natureza sempre disponível à extração material, exerce impactos definitivos sobre os ecossistemas e a atmosfera terrestre. Indica, ademais, que a fase neoliberal do capitalismo tem promovido uma "nova rodada de cercamentos", com a mercadorização crescente de recursos naturais. No que tange ao segundo, discute as condições tanto jurídico-legais quanto geopolíticas que embasaram o capitalismo industrial nascente, a hegemonia do welfare state em meados do século 20 e as atuais tendências neoliberais.

No artigo em que desenvolve tal argumento, Fraser não mobiliza o quadro conceitual que construíra anteriormente para teorizar sobre a justiça social de modo imbricado aos conflitos sociopolíticos. Não obstante, é plausível especular como cada uma dessas precondições ajuda a explicitar as mediações entre economia política, valoração social e institucionalidade estatal. Esse exercício poderia aprimorar ainda mais a construção de seu modelo, sendo válido levantar hipoteticamente alguns exemplos não exaustivos.

A questão da acumulação primitiva pode conduzir a uma análise que concatene a gênese e reprodução do capitalismo aos processos de racialização subjacentes às formas coloniais e imperiais de domínio e influência internacional; desse modo, poderia conduzir a uma crítica dos fundamentos raciais da divisão internacional do trabalho (Quijano, 2010) que demonstre a presença de um elemento irredutível de "reconhecimento" na base da injustiça distributiva do capitalismo mundial. Analogamente, a condição posta pela reprodução social - mais profundamente discutida pela autora - ajudaria a concatenar analiticamente a crítica das injustiças distributivas e valorativas, posto que desvela uma divisão sexual do trabalho justificada por uma representação inferiorizante do "feminino". Outrossim, a questão das condições jurídico-legais do capitalismo remonta a antigas análises já desenvolvidas no seio do próprio marxismo, abrindo caminho para discutir as mediações entre "redistribuição" e "representação" pela exploração da dialética entre forma e conteúdo do direito burguês. Finalmente, o tema da exploração da natureza pode ser vinculado tanto com a racialização - manifestas nas 
críticas contemporâneas ao racismo ambiental - quanto à abrangente negação à paridade participativa das gerações futuras, que perpassa os três âmbitos analíticos.

Em suma, é inegável que Fraser logra relevantes avanços ao promover revisões nessas três vias. Após uma década e meia conduzindo seu modelo crítico a discussões mais próprias do "reconhecimento" e da "representação", os textos dos anos de 2010 têm se voltado a contemplar a economia política. Entretanto, parece também claro que as respostas alcançadas nitidamente não respondem todas as indagações levantadas.

\section{Conclusão}

Não parece haver dúvidas que o âmbito político-econômico, ainda que tardiamente, passou a ser teorizado com mais cuidado por Fraser. Tampouco que suas formulações ulteriores enriqueceram seu argumento e fortaleceram a justificação quanto à articulação necessária entre políticas redistributivas, de reconhecimento e de representação. Ademais, é notório o potencial teórico que sua proposta mais recente carrega para a construção de diagnósticos quanto às imbricações e determinações entre capitalismo, colonialismo, racialização, generificação e exploração ambiental.

Fraser, assim, abre um espaço maior do que o modelo de Luta por reconhecimento para abrigar as formas especificamente capitalistas de opressão e dominação, ${ }^{3}$ fundadas em uma forma específica de relações de produção e promotoras de implicações específicas para as subjetividades e intersubjetividades; entretanto, não realiza um tratamento da questão no seio da discussão político-econômica propriamente dita. Sua discussão das condições de fundo, embora relevante para transcender uma concepção economicista de justiça social, só aborda tangencialmente os problemas da exploração, marginalização e privação que anunciara ao propor seu conceito de redistribuição. Ao mesmo tempo em que busca em Marx respaldo e autoridade para seu argumento, foge dele ao evitar um tratamento mais profundo das relações trabalhistas e do momento específico da produção dos meios de vida. Tratamento cuja necessidade pode ser justificada pela crítica da própria autora às tendências contemporâneas, socioteóricas e políticas, de minimização ou lateralização da opressão material.

\footnotetext{
${ }^{3}$ Cabe ressalvar que em obras tardias, como Direito da liberdade e $A$ ideia de socialismo, Honneth coloca a esfera econômica em discussão mais pormenorizada, teorizando quanto as condições pelas quais as relações de produção e consumo podem constituir espaços para o exercício de uma liberdade intersubjetivamente experienciada.
} 
Assim como apenas tangencia Marx sem levá-lo às últimas consequências, faz o mesmo em relação à crítica pós-colonial: ajuda a abrir espaço para a inserção da racialização e sua perpetuação em nível mundial enquanto elementos constitutivos da dominação moderna, mas evita vincular as gêneses da ideia de raça, do capitalismo e do colonialismo. Fazê-lo implicaria em contradizer tanto sua opção weberiana em tratar "cultura", "economia" e "política" como esferas de lógicas distintas que se vinculam contingencialmente, quanto seu problemático e eurocêntrico recorte que coloca as "fontes transnacionais de injustiça" como questão emergente nos últimos trinta anos; afinal, abundam trabalhos críticos indicando que nas sociedades periféricas a divisão internacional do trabalho faz engendrar injustiças de "redistribuição, reconhecimento e representação" desde o período colonial.

No mais, problemas como a generalização da experiência estadunidense não encontram solução. A princípio, poder-se-ia argumentar que apenas seu conceito normativo nuclear (a paridade participativa) é dotado de teor universalizante, enquanto a análise de seus obstáculos deve ser feita segundo a imanência do conflito social de cada espaço-temporalidade; assim, a tripartição socioanalítica - que supõe certo estágio de especialização institucional seria resultante de uma diferenciação não necessariamente generalizável. Entretanto, ao mobilizar o mesmo arcabouço para um estudo da exclusão social no sul global (Fraser, 2010), a autora parece assumir a generalidade de suas categorias.

De todo modo, mesmo considerando os necessários aprimoramentos que tais objeções ainda impõem ao modelo, bem como as adaptações e atualizações indispensáveis para estudos de conjunturas periféricas, não deixam de ser consideráveis os avanços alcançados pela autora no período recente. Convergindo com a pretensão de Amy Allen (2016) em descolonizar a Teoria Crítica, as revisões de Fraser abrem espaço para uma interlocução mais profícua não apenas com os "novos movimentos sociais", mas também com a vasta crítica pós-colonial e antirracista, sobretudo suas vertentes que não perderam de vista a dimensão material da opressão capitalista moderna. Por tudo isso, o movimento recente da autora em repensar a redistribuição parece ter provido de novo fôlego um modelo crítico que parecia aprisionado em seus limites.

\section{Referências}

ALCOFF, Linda M. Fraser on redistribution, recognition and identity. European Journal of Political Theory, v. 6, n. 3, p. 255-265, 2007.

ALLEN, Amy. The end of progress. New York: Columbia University Press, 2016. 
BENHABIB, Seyla. The claims of culture. New Jersey: Princeton University Press, 2002.

BUTLER, Judith. Merely Cultural. New Left Review, n. 227, p. 33-44, 1998.

FRASER, Nancy. Recognition or redistribution? Journal of Political Philosophy, v. 3 , n. 2, p. 166-180, $1995<10.1111 /$ j.1467-9760.1995.tb00033.x>.

FRASER, Nancy. Justice interruptus. New York: Routledge, 1997.

FRASER, Nancy. Rethinking recognition. New Left Review, n. 3, p. 107-120, 2000.

FRASER, Nancy. Da redistribuição ao reconhecimento? In: Jessé Souza (org.). Democracia hoje. Brasília: UnB, 2001.

FRASER, Nancy. Social justice in the age of identity politics. In: Axel Honneth; Nancy Fraser. Redistribution or recognition? London: Verso, 2003a.

FRASER, Nancy. Distorted beyond all recognition. In: Axel Honneth; Nancy Fraser. Redistribution or recognition? London: Verso, 2003b.

FRASER, Nancy. Reconhecimento sem ética? Lua Nova, São Paulo, n. 70, 101-138, 2007a.

FRASER, Nancy. Mapeando a imaginação feminista. Revista Estudos Feministas, n. 15 , p. 291-308, 2007b.

FRASER, Nancy. Scales of justice. New York: Columbia University Press, 2009a.

FRASER, Nancy. O feminismo, o capitalismo e a astúcia da história. Mediações, V. 14, n. 2, p. 11-33, 2009b.

FRASER, Nancy. Injustice at intersecting scales: on social exclusion and the global poor. European Journal of Social Theory, n. 13, p. 363-371, 2010 $<10.1177 / 1368431010371758>$.

FRASER, Nancy. Mercantilização, proteção social e emancipação. Revista Direito $G V$, n. 7, p. 617-634, 2011.

FRASER, Nancy. Por trás do laboratório secreto de Marx. Direito \& Práxis, v. 6, n. 10, p. 704-728, $2015<10.12957 /$ dep.2015.15431>.

FORST, Rainer. First things first. In: Kevin Olson; Nancy Fraser. Adding insult to injury: Nancy Fraser debates her critics. London: Verso, 2008. p. 310-326.

HONNETH, Axel. Luta por reconhecimento. São Paulo: Editora 34, 2003 a.

HONNETH, Axel; FRASER, Nancy. Redistribution or recognition? London: Verso, 2003b.

HONNETH, Axel; ANDERSON, Joel. Autonomia, vulnerabilidade, reconhecimento e justiça. Cadernos de Filosofia Alemã, n. 17, p. 81-112, 2011.

MATTOS, Patrícia. A Sociologia politica do reconhecimento. São Paulo, Annablume, 2006.

MARX, Karl. Grundrisse. São Paulo: Boitempo, 2011.

MENDONÇA, Ricardo Fabrino. Reconhecimento em debate. Revista de Sociologia Política, n. 29, p. 169-185, 2007. 
OLSON, Kevin. Participatory parity and democratic justice. In: Kevin Olson; Nancy Fraser. Adding insult to injury: Nancy Fraser debates her critics. London: Verso, 2008. p. 246-272.

OLSON, Kevin; FRASER, Nancy (orgs.). Adding insult to injury: Nancy Fraser debates her critics. London: Verso, 2008.

PINTO, Céli Regina Jardim. Nota sobre a controvérsia Fraser-Honneth informada pelo cenário brasileiro. Lua Nova, n. 74, p. 35-58, 2008.

POLANYI, Karl. The great transformation: the political and economic origins of our time. 2. ed. Boston: Beacon Press, 2001.

QUIJANO, Aníbal. Colonialidade do poder e classificação social. In: Boaventura de Souza Santos; Maria Paula Meneses (orgs.). Epistemologias do sul. São Paulo: Cortez, 2010. p. 84-130.

SILVA, Josué Pereira. Trabalho, cidadania e reconhecimento. São Paulo: Annablume, 2008.

SOUZA, Jessé. Uma teoria crítica do reconhecimento. Lua Nova, n. 50, p. 133-158, 2000. $<10.1590 / \mathrm{S} 0102-64452000000200008>$.

SOUZA, Luiz Gustavo da Cunha de. Reconhecimento como teoria crítica? Campinas, Universidade Estadual de Campinas, 2009. Dissertação de mestrado em Sociologia.

SOUZA, Luiz Gustavo da Cunha de. Reconhecimento, redistribuição e as limitações da teoria crítica contemporânea. Campinas: Universidade Estadual de Campinas, 2013. Tese de doutorado em Sociologia.

TAYLOR, Charles. Argumentos filosóficos. São Paulo: Edições Loyola, 2000.

WEBER, Max. Ensaios de sociologia. 5. ed. Rio de Janeiro: Zahar, 1982.

YOUNG, Iris M. Unruly categories. New Left Review, n. 222, p. 147-160, 1997.

ZURN, Christopher. Arguing over participatory parity. In: Kevin Olson; Nancy Fraser (orgs.). Adding insult to injury: Nancy Fraser debates her critics. London: Verso, 2008. p. 176-189.

Recebido em: 29 jan. 2018

Aprovado em: 27 set. 2018

Endereço do autor:

Enrico Paternostro Bueno da Silva

Rua Boa Morte, 1835

13400-530 Piracicaba SP, Brasil

ENRICO PATERNOSTRO BUENO DA SILVA <enricobueno@yahoo.com.br>

Doutorando em Sociologia na Universidade Estadual de Campinas (Unicamp, Campinas, SP, Brasil), professor da Faculdade Dom Bosco (Piracicaba, SP, Brasil).

ORCID: http://orcid.org/0000-0002-3822-8209 